\title{
Predictors of treatment with antibiotics and systemic corticosteroids for acute exacerbations of asthma and chronic obstructive pulmonary disease in primary care
}

\author{
Salwan Al-ani ${ }^{*}$, Mark Spigt ${ }^{1,2}$, Johanna Laue ${ }^{1}$ and Hasse Melbye ${ }^{1}$
}

\begin{abstract}
Background: Antibiotic and oral corticosteroid prescribing rate in patients suffering from acute exacerbations of chronic obstructive pulmonary disease (COPD) or asthma in general practice are only sparsely described. Our aim was to identify predictors for such prescribing when results from CRP testing, spirometry, and pulse oximetry are available.

Methods: Patients aged 40 years or more diagnosed with asthma, COPD or both, the previous five years from seven general practice offices in Norway, were invited to a baseline examination and asked to visit their GPs during exacerbations the following 12 months. At all visits, symptoms, chest findings, and results from spirometry, pulse oximetry and CRP testing were registered.

Results: Out of the 376 who took part in baseline examination, 95 patients with an exacerbation were included in the analysis. Based on the diagnosis made by GPs, 46 patients (48.4\%) were only registered with asthma, and 49 (51.6\%) with COPD (or both diagnosis). 11 patients had taken antibiotics and 16 had taken systemic corticosteroids prior to their visit to their GPs. After excluding those already treated, antibiotics were prescribed in $34.9 \%$ and systemic corticosteroids in $42.5 \%$ of patients diagnosed with COPD compared to $14.6 \%$ and $30.8 \%$ respectively in patients only diagnosed with asthma ( $P=0.02, P=0.2)$. In the COPD group, antibiotic prescribing was not significantly associated with purulence or other respiratory symptoms, but increased phlegm was a significant predictor of antibiotic prescribing in the whole sample $(P=0.04)$. Prolonged expiration, wheezes and diminished breath sounds also predicted the prescribing of both antibiotics and systemic corticosteroids in the whole sample with $P$ values $<0.01$. The prescribing rate of antibiotics and systemic corticosteroids also increased with increasing CRP value $(P=0.001$ and $P=0.01$, respectively) and with decreasing oxygen saturation $(P=0.01$ and $P=0.003$, respectively). $F V_{1} / F V C<0.7$ at baseline was as significant predictor in patients with COPD and in the whole sample of patients regarding treatment with antibiotics ( $P=0.004$ and $P=0.001$, respectively) and treatment with systemic corticosteroids ( $P=0.004$ and $P=0.001$, respectively).
\end{abstract}

Conclusion: Chest findings, raised CRP value and decreased oxygen saturation were stronger predictors of prescribing of antibiotics and systemic corticosteroids than were respiratory symptoms. Further evaluation of the importance of these findings to guide treatment of asthma and COPD exacerbations is warranted.

Keywords: COPD, Asthma, Exacerbations, Antibiotics, Systemic corticosteroids

\footnotetext{
*Correspondence: salwan.t.al-ani@uit.no

'General practice research unit, Department of Community Medicine, UIT Arctic University of Norway, Tromso, Norway

Full list of author information is available at the end of the article
} 


\section{Background}

Chronic obstructive pulmonary disease (COPD) is a huge health problem and it is expected to become an even bigger problem due to the rapidly ageing population worldwide [1]. The course of COPD is usually punctuated by episodes of acute worsening of respiratory symptoms, known as acute exacerbations (AECOPD). Among persons older than 40 years in Norway, spirometry revealed COPD in 18\% [2], most of them have mild COPD and not more than $4 \%$ are registered with a COPD diagnosis in Norwegian primary care [3]. Patients with asthma also experience exacerbation of their disease, which is characterized by a progressive increase in respiratory symptoms and progressive decrease in lung function sufficient to require a change in treatment [4]. The prevalence of asthma has increased both for children and adults in Norway. It is estimated that $8 \%$ of all adults have the disease [5]. In a study on asthma exacerbations, $8.8 \%$ of the patients experienced an exacerbation of their asthma during a 3 months period [6]. We have previously reported that in Norwegian COPD patients $46.8 \%$ experienced one exacerbation or more in one year [7], similar to the frequency found in an international study [8].

Although both COPD and asthma involves bronchial inflammation and airway limitation, we know that the underlying pathophysiology differs $[9,10]$, but in real life, it is still difficult to differentiate between these diseases [3] and a combination of the two diseases may occur $[3,11]$.

Although the trigger for severe exacerbations in patients with COPD cannot be identified in almost one third of cases, bacterial infection, viral infection and environmental pollutants are triggers in the other two thirds [12] and it is estimated that 50 to $70 \%$ of the exacerbations of COPD have an infectious etiology [13]. The standard treatment of AECOPD is usually short-acting bronchodilators, oral corticosteroids and/or antibiotics depending on the presenting symptoms. Antibiotic treatment in patients with AECOPD has been a matter of debate in many years mainly due to difficulties in defining exacerbations and in demonstrating their bacterial etiology. Anthonisen and colleagues divided the exacerbations into three types based on the increase of the three cardinal symptoms: dyspnea, phlegm and purulence with type 1 being the most severe (all three symptoms) [14]. Recent work has shown correlation between sputum purulence and the presence of bacteria [15]. Therefore, the current guidelines recommend antibiotic therapy to Anthonisen type 1 patients and to those with two of the three cardinal symptoms, if increased purulence of phlegm is one of them $[13,14,16]$.

Exacerbations of asthma usually occur in response to an external stimulus (viral upper respiratory tract infection or

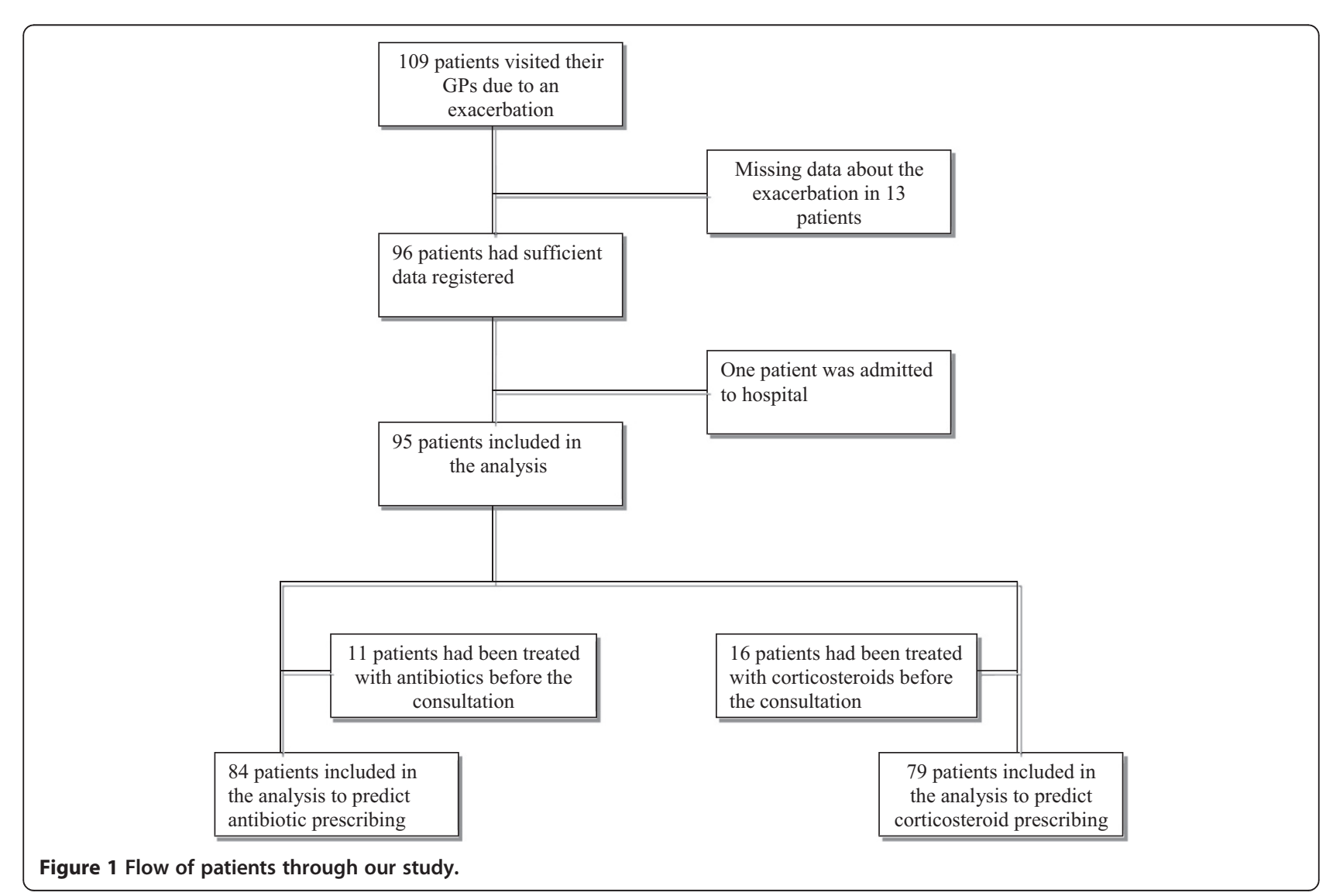


pollution) and in patients with poor compliance, but can also occur in patients with mild and well-controlled asthma [17]. The assessment of the severity of an asthma exacerbation is usually based on symptoms and physical examination. Lung function and oxygen saturation may also be measured [18]. Correction of hypoxemia, rapid reversal of airway obstruction and reducing the risk of relapse are the main targets for treatment of asthma exacerbations [19]. Short-acting bronchodilators, oral corticosteroids and oxygen, if the patient is hypoxemic, are the main treatment options. Antibiotic therapy is not recommended if the patient does not have pneumonia or other bacterial infections at the same time [18].

More antibiotic prescribing than recommended in COPD guidelines was found in a Dutch study from 2006 [20]. In a cross-sectional study carried out in 6 countries in 2008, Llor et al found that the antibiotic prescribing rate was 78.7\% among patients with AECOPD, being higher in patients with type 1 Anthonisen (94.2\%), followed by type 2 (84.1\%) and type 3 (65.8\%). Even patients that did not have any Anthonisen criteria received antibiotics (42.5\%) [21]. In all the Anthonisen groups, less antibiotics were prescribed to patients tested with $\mathrm{C}$-reactive protein (CRP).

Due to the risk of microbial resistance development [22] and the side effects of both antibiotics and systemic corticosteroids $[23,24]$, unnecessary use of these treatments should be avoided.

In this study the patients with COPD or asthma exacerbations were, as a routine, tested with the following three biomarkers: CRP test, spirometry and pulse oximetry. We wanted to find out whether the GPs took the results of these tests into account when prescribing antibiotics and systemic corticosteroids, and aimed at determining the predictive value of the biomarkers for such prescribing, also when added to respiratory symptoms and chest signs.

\section{Methods}

This is an observational multicenter prospective cohort study with a baseline registration and a 12 months follow-up period in primary care to investigate the predictors for treatment with antibiotics and systemic corticosteroids in patients with exacerbation of asthma or COPD.

\section{Setting and participants}

Patients from seven general practice offices who were 40 years or older with a diagnosis of asthma or COPD registered in their medical record the previous five years were invited to a baseline study. Out of 380 patients who met between April 2009 and March 2010, 376 were deemed to be in a stable phase of their illness and performed post-bronchodilator spirometry, 210 had been diagnosed with asthma only and 166 with COPD (including 92 with both diagnosis) [3,7]. The GPs recorded whether or not treatment with antibiotics and/or systemic corticosteroids had been prescribed for an exacerbation the previous 12 months, and the patients reported hospitalizations due to exacerbations during the same period. Smoking status and comorbidities were registered. All participants were asked to contact their GP during exacerbations the

Table 1 Characteristics of the 95 patients taking part in the study

\begin{tabular}{|c|c|c|c|}
\hline & $\begin{array}{l}\text { Asthma } \\
n(\%)\end{array}$ & $\begin{array}{l}\text { COPD/Both } \\
n(\%)\end{array}$ & All $n(\%)$ \\
\hline All & $46(48.4)$ & $49(51.6)$ & $95(100)$ \\
\hline Age 65 years or more & $17(37.0)$ & $28(57.1)$ & $45(47.4)$ \\
\hline \multicolumn{4}{|l|}{ Gender } \\
\hline Male & $17(37.0)$ & $18(36.7)$ & $35(36.8)$ \\
\hline Female & $29(63.0)$ & $31(63.3)$ & $60(63.2)$ \\
\hline \multicolumn{4}{|l|}{ Smoking status } \\
\hline Never smoker & $18(39.1)$ & $8(16.3)$ & $26(27.4)$ \\
\hline Current smoker & $12(26.1)$ & $18(36.7)$ & $30(31.6)$ \\
\hline Ex-smoker & $16(34.8)$ & $23(46.9)$ & $39(41.1)$ \\
\hline \multicolumn{4}{|l|}{ Spirometry at baseline } \\
\hline $\mathrm{FEV}_{1} / \mathrm{FVC}<0.7$ & $7(15.2)$ & $32(65.3)$ & $39(41.1)$ \\
\hline \multicolumn{4}{|l|}{ Respiratory symptoms } \\
\hline $\begin{array}{l}\text { Dyspnea, bothersome or very } \\
\text { bothersome }\end{array}$ & $42(91.3)$ & $47(95.9)$ & $89(93.7)$ \\
\hline very bothersome & $12(26.1)$ & 19 (38.8) & $31(32.6)$ \\
\hline $\begin{array}{l}\text { Phlegm, bothersome or very } \\
\text { bothersome }\end{array}$ & $35(76.1)$ & $36(73.5)$ & $71(74.7)$ \\
\hline very bothersome & $9(19.6)$ & $9(18.4)$ & $18(18.9)$ \\
\hline Purulence & $23(50.0)$ & $21(42.9)$ & $44(46.3)$ \\
\hline $\begin{array}{l}\text { Coughing, bothersome or very } \\
\text { bothersome }\end{array}$ & $42(91.3)$ & $43(87.8)$ & $85(89.5)$ \\
\hline very bothersome & $16(34.8)$ & $15(30.6)$ & $31(32.6)$ \\
\hline \multicolumn{4}{|l|}{ Chest findings } \\
\hline Prolonged expiration & $16(34.8)$ & $26(53.1)$ & $42(44.2)$ \\
\hline Wheezes/rhonchi & $16(34.8)$ & $31(63.3)$ & $47(49.5)$ \\
\hline Diminished breath sounds & $4(8.7)$ & 15 (30.6) & $19(20.0)$ \\
\hline Crackles & $10(21.7)$ & $18(36.7)$ & $28(29.5)$ \\
\hline Any abnormal chest finding & $24(52.2)$ & 39 (79.6) & $63(66.3)$ \\
\hline $\begin{array}{l}\text { Admitted to hospital due to } \\
\text { exacerbation the year before } \\
\text { baseline }\end{array}$ & $3(6.6)$ & $3(6.1)$ & $6(6.4)$ \\
\hline $\begin{array}{l}\text { Exacerbation treated with } \\
\text { antibiotics the year before } \\
\text { baseline }\end{array}$ & $13(28.3)$ & $24(49.0)$ & $37(38.9)$ \\
\hline $\begin{array}{l}\text { Exacerbation treated with } \\
\text { systemic corticosteroids } \\
\text { the year before baseline }\end{array}$ & $7(15.2)$ & $24(49.0)$ & 31 (32.6) \\
\hline
\end{tabular}


following 12 months. More details about the baseline registration have previously been reported [7].

The regional committee for Medical and Health Research Ethics in North Norway approved the study. All study participants gave written consent.

COPD exacerbation was defined as an increase in dyspnea, coughing or sputum amount that is acute in onset and beyond normal day-to-day variations, which necessitates a dosage adjustment of medication [12]. Asthma exacerbations were defined as episodes of a progressive increase in shortness of breath, cough, wheezing, or chest tightness or a combination of these symptoms [19]. The patients were asked to consult their GPs within 2-3 days when they experience such an increase in symptoms. For patients who visited the GP with several exacerbations during follow up, the first exacerbation was, as a rule, included in the analysis. A later exacerbation was chosen if the set of data from the first exacerbation was not sufficiently complete.

When the patient consulted during an exacerbation, the GPs registered and graded the patient's symptoms, chest findings, and the duration of the exacerbation and whether the patient had taken antibiotics or systemic corticosteroids the preceding days. Spirometry, CRP and oxygen saturation were also measured during the consultation.

Spirometry was performed according to the American Thoracic Society/European Respiratory Society guidelines [25], using a Spirare SPS310 Spirometer (Diagnostica AS,
Oslo, Norway). The CRP rapid test was carried out using Afinion AS100 Analyzer (Axis-Shield, Scotland), Orion Quickread CRP (Orion Diagnostica Oy, Espoo, Finland), or ABX Micros CRP (HORIBA medical, Montpellier, France), oxygen saturation was measured by a digital handheld pulse oximeter, Onyx II model 0550 (Nonin Medical Inc., Plymouth, MN, USA).

\section{Statistical analysis}

The frequencies of prescribed treatment by patient's characteristics and clinical findings were analyzed separately in patients only diagnosed with asthma (the asthma group) and in patients diagnosed with COPD or both asthma and COPD (the COPD group). Patients, who had started treatment with antibiotic or oral corticosteroids, respectively, before the consultation, were excluded when predictors of prescribing antibiotic and corticosteroid treatment at the consultation were analyzed. When comparing the prescribing between subgroups, Fisher's Exact Test was used for $2 \times 2$ tables and Chi square statistics when continuous variables had been categorized into more than two categories, usually examining linear-bylinear association. Multivariable logistic regression was done in the whole patient sample with antibiotic prescribing as outcome, adding CRP to relevant symptoms, signs and COPD status at baseline in the explanatory model. Likewise pulse oximetry results were added to symptoms, signs and COPD status in a model with systemic corticosteroid prescribing as outcome. Goodness-of-fit was tested

\section{All patients}

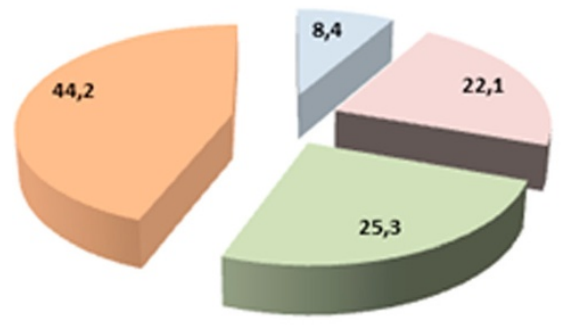

Asthma patients



Antibiotics, no systemic corticosteroids

Systemic corticosteroids, no antibiotics

Both antibio tics and systemic corticosteroids

No treatment

\section{COPD/Both COPD and asthma}

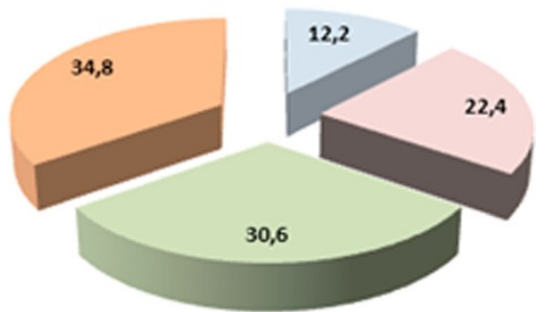

Figure 2 Percentages of 95 patients treated with antibiotics, systemic corticosteroids or both, which includes the treatment taken before the consultaion. 
Table 2 Antibiotic prescribing by patient characteristics for exacerbations of asthma (41 patients) and COPD (43 patients)

\begin{tabular}{|c|c|c|c|c|c|c|}
\hline & Asthma n (\%) & $P$-value & COPD/Both n (\%) & $P$-value & All $n(\%)$ & $P$-value \\
\hline All & $6 / 41(14.6)$ & & 15/43 (34.9) & & $21 / 84(25.0)$ & \\
\hline \multicolumn{7}{|l|}{ Baseline characteristics } \\
\hline \multicolumn{7}{|l|}{ Age } \\
\hline$\geq 65$ years & $1 / 13(7.7)$ & 0.4 & $9 / 25(36.0)$ & 0.6 & 10/38 (26.3) & 0.5 \\
\hline$<65$ years & $5 / 28(17.9)$ & & 6/18 (33.3) & & $11 / 46(23.9)$ & \\
\hline \multicolumn{7}{|l|}{ Gender } \\
\hline Male & $3 / 15(20.0)$ & 0.4 & $5 / 16(31.3)$ & 0.5 & $8 / 31(25.8)$ & 0.5 \\
\hline Female & $3 / 26(11.5)$ & & 10/27 (37.0) & & $13 / 53(24.5)$ & \\
\hline \multicolumn{7}{|l|}{ Smoking status } \\
\hline Never smoker & 2/15 (13.3) & $0.6^{*}$ & 2/8 (25.0) & $0.7^{*}$ & $4 / 23(17.4)$ & $0.8^{*}$ \\
\hline Current smoker & $3 / 11(27.3)$ & & $8 / 16(50.0)$ & & $11 / 27(40.7)$ & \\
\hline Ex-smoker & $1 / 15(6.7)$ & & $5 / 19(26.3)$ & & 6/34 (17.6) & \\
\hline \multicolumn{7}{|l|}{ Spirometry } \\
\hline $\mathrm{FEV}_{1} / \mathrm{FVC}<0.7$ & $3 / 7(42.9)$ & 0.05 & $13 / 27(48.1)$ & 0.02 & $16 / 34(47.1)$ & $<0.001$ \\
\hline \multicolumn{7}{|l|}{ Characteristics at exacerbation } \\
\hline \multicolumn{7}{|l|}{ Respiratory symptoms } \\
\hline Dyspnea, bothersome or very bothersome & $6 / 38(15.8)$ & 0.6 & 15/41 (36.6) & 0.4 & 21/79 (26.6) & 0.2 \\
\hline very bothersome & 2/9 (22.2) & 0.4 & $6 / 15(40.0)$ & 0.4 & 8/24 (33.3) & 0.2 \\
\hline Phlegm, bothersome or very bothersome & $6 / 30(20.0)$ & 0.1 & 13/32(40.6) & 0.2 & 19/62 (30.6) & 0.04 \\
\hline very bothersome & 2/7 (28.6) & 0.3 & $4 / 6(66.7)$ & 0.09 & $6 / 13(46.2)$ & 0.06 \\
\hline Purulence & $4 / 19(21.1)$ & 0.3 & 6/18 (33.3) & 0.5 & $10 / 37(27.0)$ & 0.4 \\
\hline Coughing, bothersome or very bothersome & 6/38 (15.8) & 0.6 & 14/38 (36.8) & 0.4 & 20/76 (26.3) & 0.3 \\
\hline very bothersome & $2 / 14(14.3)$ & 0.7 & $6 / 12(50.0)$ & 0.2 & $8 / 26(30.8)$ & 0.3 \\
\hline \multicolumn{7}{|l|}{ Anthonisen criteria combined } \\
\hline Type III & $0 / 10(0)$ & $0.08^{*}$ & $2 / 10(20.0)$ & $0.4^{*}$ & $2 / 20(10.0)$ & $0.1^{*}$ \\
\hline Type II & 2/15 (13.3) & & $7 / 17(41.2)$ & & $9 / 32(28.1)$ & \\
\hline Type I & $4 / 16(25.0)$ & & $6 / 16(37.5)$ & & 10/32 (31.3) & \\
\hline Chest findings Prolonged expiration & 4/14 (28.6) & 0.09 & $11 / 23(47.8)$ & 0.06 & $15 / 37(40.5)$ & 0.004 \\
\hline Wheezes/rhonchi & $4 / 15(26.7)$ & 0.1 & $12 / 27(44.4)$ & 0.08 & $16 / 42(38.1)$ & 0.005 \\
\hline Diminished breath sounds & $2 / 4(50.0)$ & 0.09 & 7/13 (53.8) & 0.08 & $9 / 17(52.9)$ & 0.005 \\
\hline Crackles & 2/9 (22.2) & 0.4 & 7/16 (43.8) & 0.3 & $9 / 25(36.0)$ & 0.1 \\
\hline Any abnormal chest finding & $4 / 22(18.2)$ & 0.4 & $14 / 34(41.2)$ & 0.09 & $18 / 56(32.1)$ & 0.03 \\
\hline \multicolumn{7}{|l|}{ Lung function $^{a}$} \\
\hline $\mathrm{FEV}_{1} \%$ predicted $<50$ & $0 / 1(0)$ & $0.9^{*}$ & $3 / 10(30.0)$ & $0.7^{*}$ & $3 / 11(27.3)$ & $0.2^{*}$ \\
\hline $\mathrm{FEV}_{1} \%$ predicted $50-80$ & $2 / 10(20.0)$ & & $10 / 25(40.0)$ & & $12 / 35(34.3)$ & \\
\hline $\mathrm{FEV}_{1} \%$ predicted $\geq 80$ & $4 / 25(16.0)$ & & $1 / 6(16.7)$ & & $5 / 31(16.1)$ & \\
\hline \multicolumn{7}{|l|}{ C-reactive protein ${ }^{b}$} \\
\hline$<8 \mathrm{mg} / \mathrm{L}$ & $4 / 24(16.7)$ & $0.9^{*}$ & $3 / 24(12.5)$ & $<0.001^{*}$ & $7 / 48(14.6)$ & $0.001^{*}$ \\
\hline 8-39 mg/L & 2/11 (18.2) & & $6 / 10(60.0)$ & & $8 / 21(38.1)$ & \\
\hline$\geq 40 \mathrm{mg} / \mathrm{L}$ & $0 / 1(0)$ & & $5 / 6(83.3)$ & & $5 / 7(71.4)$ & \\
\hline
\end{tabular}

Oxygen saturation $\left(\mathrm{SpO}_{2}\right)^{\mathrm{c}}$ 
Table 2 Antibiotic prescribing by patient characteristics for exacerbations of asthma (41 patients) and COPD (43 patients) (Continued)

\begin{tabular}{lllll}
\hline$>95 \%$ & $5 / 27(18.5)$ & $0.3^{*}$ & $6 / 23(26.1)$ & $0.06^{*}$ \\
$93-95 \%$ & $0 / 3(0)$ & $1 / 8(12.5)$ & $0.01^{*}$ & $1 / 11(9.1)$ \\
$<93 \%$ & $1 / 1(100)$ & $6 / 9(66.7)$ & $7 / 10(70.0)$ \\
\hline
\end{tabular}

* $P$-value calculated using linear-by-linear Chi-Square tests otherwise $P$-value calculated using Fisher's Exact Test.

a 7 missing, 5 in asthma group and 2 in the COPD/Both group.

${ }^{\mathrm{b}} 8$ missing, 5 in asthma group and 3 in the COPD/Both group.

${ }^{c} 13$ missing, 10 in asthma group and 3 in the COPD/Both group.

by Hosmer and Lemeshow statistics. Statistical analysis was performed using the SPSS version 19 (IBM, Armonk, NY, USA).

\section{Results}

During the one-year follow-up period, 109 patients visited their GP due to one or more exacerbations. Of these, 14 patients were excluded due to incomplete data, and 95 patients were included in the analysis (Figure 1), $63.2 \%$ were female and $47.4 \%$ were 65 years or older (mean age 62.1 years). Based on the diagnosis made by the GPs, 46 patients (48.4\%) were only registered with asthma, and 49 patients (51.6\%) with COPD (or both diagnoses). $\mathrm{FEV}_{1} / \mathrm{FVC}<0.7$ post-bronchodilator had been found at baseline in 39 of the patients $(41.1 \%$, mean age 65.2 years); whereas 56 patients $(58.9 \%)$ had $\mathrm{FEV}_{1} / \mathrm{FVC} \geq$ 0.7 (mean age 59.9 years). Other baseline characteristics are shown in Table 1.

During exacerbation, bothersome or very bothersome dyspnea was the most frequent symptom recorded by the GPs in the whole sample of patients whether diagnosed with asthma or not, followed by coughing and phlegm (Table 1). Purulence was recorded in $42.9 \%$ in the COPD group and in $50 \%$ in the asthma group. Of the chest findings, wheezes and prolonged expiration were most frequently registered. When adding medication taken prior to the consultation, $8.4 \%$ of the included patients were treated with antibiotics alone, $22.1 \%$ were treated with systemic corticosteroids alone, and 25.3\% were treated with both medications (Figure 2). Patients in the COPD group were treated more often with antibiotics and systemic corticosteroids than those in the asthma group (Figure 2).

\section{Predictors of antibiotic prescribing}

Antibiotic prescribing in the whole sample of patients increased with increasing symptom load from $10 \%$ in patients with Anthonisen type III, to $28.1 \%$ in type II and $31.3 \%$ in patients with type I $(P=0.1$, Table 2$)$. This association was still not statistically significant when the analysis was done separately in the asthma and COPD groups. Among COPD patients with purulence, $33.3 \%$ were prescribed antibiotics $(P=0.5)$, whereas the corresponding figure in COPD patients with bothersome or very bothersome phlegm was
40.6\% $(P=0.2)$, and phlegm was a significant predictor of antibiotic prescribing in the whole sample $(P=0.04)$. All the chest findings except crackles were significant predictors of antibiotic prescribing in the whole sample of patients (Table 2). The prescribing rate increased with increasing CRP value in the COPD group and in the whole sample of patients as shown in (Table 2). The same trend was found regarding oxygen saturation, with increased prescribing rate in patients with oxygen saturation less than 93\%. The strong association between antibiotic prescribing and both baseline FEV1/ FVC $<0.7$ and raised CRP values were confirmed by the multivariable analysis (Table 3 ). The $P$-value of the Hosmer and Lemeshow goodness-of-fit test was 0.6.

\section{Predictors of prescribing systemic corticosteroids}

Being 65 years old or more was a significant predictor of prescribing systemic corticosteroids only in patients with asthma, $P=0.03$ (Table 4). Of the symptoms recorded by GPs, very bothersome dyspnea and coughing predicted the treatment with systemic corticosteroids in patients in the COPD group, but not in the asthma group. Crackles were the only chest finding predicting treatment with systemic corticosteroids in the COPD group $(P=0.003)$, while prolonged expiration and diminished breath sounds were significant in predicting this type of treatment in patients with asthma (Table 4). All the patients with $\mathrm{C}$-reactive protein $(\mathrm{CRP}) \geq 40$ were treated with systemic corticosteroids regardless diagnosis, and the prescribing rate increased with decreasing oxygen saturation in the COPD group $(P=0.004)$.

By entering FEV1/FVC $<0.7$ at baseline, very bothersome dyspnea, crackles and pulse oximetry $\leq 92 \%$ into multivariate logistic regression model (Table 5), FEV1/

Table 3 Predictors for treatment with antibiotics during exacerbations in 84 patients with asthma or COPD using multivariable logistic regression

\begin{tabular}{lll}
\hline & OR (95\%Cl) & $P$-value \\
\hline FEV $_{1} / \mathrm{FVC}<0.7$ - yes vs no & $4.6(1.3-17.1)$ & 0.02 \\
Bothersome or very bothersome phlegm & $3.1(0.5-18.3)$ & 0.2 \\
Prolonged expiration & $2.2(0.6-8.4)$ & 0.2 \\
C-reactive protein $\geq 8 \mathrm{mg} / \mathrm{L}$ - pos vs neg & $4.3(1.3-14.8)$ & 0.02 \\
\hline
\end{tabular}


Table 4 Systemic corticosteroid prescribing by patient characteristics for exacerbations of asthma (39 patients) and COPD (40 patients)

\begin{tabular}{|c|c|c|c|c|c|c|}
\hline & Asthma n (\%) & $P$-value & COPD/Both n (\%) & $P$-value & All $n(\%)$ & $P$-value \\
\hline$\overline{\text { All }}$ & $12 / 39(30.8)$ & & $17 / 40(42.5)$ & & $29 / 79(36.7)$ & \\
\hline \multicolumn{7}{|l|}{ Baseline characteristics } \\
\hline \multicolumn{7}{|l|}{ Age } \\
\hline$\geq 65$ years & $1 / 13(7.7)$ & 0.03 & $10 / 23(43.5)$ & 0.5 & $11 / 36(30.6)$ & 0.2 \\
\hline$<65$ years & $11 / 26(42.3)$ & & $7 / 17(41.2)$ & & 18/43 (41.9) & \\
\hline \multicolumn{7}{|l|}{ Gender } \\
\hline Male & $3 / 13(23.1)$ & 0.4 & $8 / 13(61.5)$ & 0.09 & $11 / 26(42.3)$ & 0.3 \\
\hline Female & 9/26 (34.6) & & 9/27 (33.3) & & 18/53 (34.0) & \\
\hline \multicolumn{7}{|l|}{ Smoking status } \\
\hline Never smoker & $3 / 16(18.8)$ & $0.5^{*}$ & $0 / 7(0)$ & $0.2^{*}$ & 3/23 (13.0) & $0.1^{*}$ \\
\hline Current smoker & $5 / 9(55.6)$ & & 10/17 (58.8) & & $15 / 26(57.7)$ & \\
\hline Ex-smoker & 4/14 (28.6) & & $7 / 16(43.8)$ & & $11 / 30(36.7)$ & \\
\hline \multicolumn{7}{|l|}{ Spirometry } \\
\hline $\mathrm{FEV}_{1} / \mathrm{FVC}<0.7$ & $3 / 5(60.0)$ & 0.1 & $15 / 25(60.0)$ & 0.004 & $18 / 30(60.0)$ & 0.001 \\
\hline \multicolumn{7}{|l|}{ Characteristics at exacerbation } \\
\hline \multicolumn{7}{|l|}{ Respiratory symptoms } \\
\hline Dyspnea, bothersome or very bothersome & $11 / 35(31.4)$ & 0.6 & $17 / 38(44.7)$ & 0.3 & 28/73 (38.4) & 0.3 \\
\hline very bothersome & $4 / 9(44.4)$ & 0.3 & $9 / 12(75.0)$ & 0.01 & 13/21 (61.9) & 0.006 \\
\hline Phlegm, bothersome or very bothersome & 10/28 (35.7) & 0.2 & $14 / 31(45.2)$ & 0.4 & $24 / 59(40.7)$ & 0.2 \\
\hline very bothersome & 2/7 (28.6) & 0.6 & 5/7 (71.4) & 0.1 & $7 / 14(50.0)$ & 0.2 \\
\hline Purulence & $7 / 17(41.2)$ & 0.2 & $7 / 18(38.9)$ & 0.2 & $14 / 35(40.0)$ & 0.4 \\
\hline Coughing, bothersome or very bothersome & $12 / 35(34.3)$ & 0.2 & $17 / 36(47.2)$ & 0.09 & 29/71 (40.8) & 0.02 \\
\hline Very bothersome & $5 / 14(35.7)$ & 0.4 & $9 / 13(69.2)$ & 0.02 & $14 / 27(51.9)$ & 0.04 \\
\hline \multicolumn{7}{|l|}{ Anthonisen criteria combined } \\
\hline Type III & 2/11 (18.2) & $0.08^{*}$ & $3 / 8(37.5)$ & $0.8^{*}$ & $5 / 19(26.3)$ & $0.1^{*}$ \\
\hline Type II & $3 / 14(21.4)$ & & $7 / 16(43.8)$ & & 10/30 (33.3) & \\
\hline Type I & $7 / 14(50.0)$ & & $7 / 16(43.8)$ & & $14 / 30(46.7)$ & \\
\hline \multicolumn{7}{|l|}{ Chest findings } \\
\hline Prolonged expiration & $7 / 13(53.8)$ & 0.03 & $12 / 23(52.2)$ & 0.1 & $19 / 36(52.8)$ & 0.006 \\
\hline Wheezes/rhonchi & $7 / 14(50.0)$ & 0.06 & $13 / 26(50.0)$ & 0.2 & 20/40 (50.0) & 0.01 \\
\hline Diminished breath sounds & 4/4 (100) & 0.006 & $7 / 12(58.3)$ & 0.2 & $11 / 16(68.8)$ & 0.004 \\
\hline Crackles & $4 / 8(50.0)$ & 0.2 & $12 / 17(70.6)$ & 0.003 & $16 / 25(64.0)$ & 0.001 \\
\hline Any abnormal chest finding & 9/21 (42.9) & 0.08 & $15 / 33(45.5)$ & 0.3 & $24 / 54(44.4)$ & 0.03 \\
\hline \multicolumn{7}{|l|}{ Lung function ${ }^{a}$} \\
\hline $\mathrm{FEV}_{1} \%$ predicted $<50$ & $0 / 1(0)$ & $0.8^{*}$ & $5 / 10(50.0)$ & $0.08^{*}$ & $5 / 11(45.5)$ & $0.1^{*}$ \\
\hline $\mathrm{FEV}_{1} \%$ predicted $50-80$ & 4/9 (44.4) & & $10 / 22(45.5)$ & & $14 / 31(45.2)$ & \\
\hline $\mathrm{FEV}_{1} \%$ predicted $\geq 80$ & $7 / 23(30.4)$ & & $0 / 6(0)$ & & $7 / 29(24.1)$ & \\
\hline \multicolumn{7}{|l|}{ C-reactive protein ${ }^{\mathrm{b}}$} \\
\hline$<8$ mg/L & $7 / 21(33.3)$ & $0.4^{*}$ & $7 / 21(33.3)$ & $0.02^{*}$ & 14/42 (33.3) & $0.01^{*}$ \\
\hline 8-39 mg/L & $4 / 11(36.4)$ & & $3 / 10(30.0)$ & & $7 / 21(33.3)$ & \\
\hline$\geq 40 \mathrm{mg} / \mathrm{L}$ & $1 / 1(100)$ & & 6/6 (100) & & 7/7 (100) & \\
\hline
\end{tabular}

Oxygen saturation $\left(\mathrm{SpO}_{2}\right)^{c}$ 
Table 4 Systemic corticosteroid prescribing by patient characteristics for exacerbations of asthma (39 patients) and COPD (40 patients) (Continued)

\begin{tabular}{|c|c|c|c|c|c|c|}
\hline$>95 \%$ & $8 / 24(33.3)$ & $0.3^{*}$ & $6 / 23(26.1)$ & $0.004^{*}$ & $14 / 47$ (29.8) & $0.003^{*}$ \\
\hline $93-95 \%$ & 1/3 (33.3) & & 2/6 (33.3) & & 3/9 (33.3) & \\
\hline$<93 \%$ & $1 / 1(100)$ & & $7 / 8(87.5)$ & & 8/9 (88.9) & \\
\hline
\end{tabular}

${ }^{*}$-value calculated using linear-by-linear Chi-Square tests otherwise $P$-value calculated using Fisher's Exact Test.

a 8 missing, 6 in asthma group and 2 in the COPD/Both group.

${ }^{\mathrm{b}} 9$ missing, 6 in asthma group and 3 in the COPD/Both group.

c14 missing, 11 in asthma group and 3 in the COPD/Both group.

FVC $<0.7$ and crackles were found to be significant predictors of prescribing. The $P$-value of the Hosmer and Lemeshow goodness-of-fit test was 0.47 .

\section{Discussion}

\section{Main findings}

Patients diagnosed with COPD or both COPD and asthma by theirs GPs at baseline, were treated more often with antibiotics and systemic corticosteroids during exacerbations than the patients only diagnosed with asthma. Most remarkably we found that the presence of purulence did not significantly predict antibiotic prescribing, not even among the COPD patients, whereas chest finding and biomarkers were significant predictors of the prescribing of both antibiotics and corticosteroids.

\section{Comparisons with other studies}

In our study increased phlegm was the only Anthonisen criterion significantly associated with antibiotic prescribing. In an international study on antibiotic treatment of COPD exacerbation by Llor et al., purulence was the strongest predictor of antibiotics prescribing in countries without access to CRP testing [21]. Where the CRP test was available purulence was still a strong predictor of antibiotic prescribing, but in contrast to our study, CRP testing was not carried out as a routine in all patients. In a British study of patients with lower respiratory tract infection, including patients with AECOPD, antibiotic prescribing was associated with both purulence and abnormal chest findings [26]. Strong emphasis laid on chest findings when prescribing antibiotics has also been reported in other previous studies [27-29].

Llor et al. found that the availability (and use) of CRP testing reduced the weight laid on the presence of

Table 5 Predictors for treatment with systemic corticosteroids during exacerbations in 79 patients with asthma or COPD using multivariable logistic regression

\begin{tabular}{lll}
\hline & OR (95\%Cl) & P-value \\
\hline $\mathrm{FEV}_{1} / \mathrm{FVC}<0.7$ - yes vs no & $3.7(1.1-11.7)$ & 0.03 \\
Very bothersome dyspnea - yes vs no & $2.9(0.8-9.9)$ & 0.09 \\
Crackles - yes vs no & $4.3(1.3-14.0)$ & 0.01 \\
Oxygen saturation $\left(\mathrm{SpO}_{2}\right)<93 \%$ - yes vs no & $5.7(0.6-56.4)$ & 0.1 \\
\hline
\end{tabular}

purulence [21], similar to that found in a study on patients with acute cough [28]. The use of the CRP in AECOPD was strongly supported in a recent study. A CRP value $>40 \mathrm{mg} / \mathrm{L}$ was the strongest predictor of treatment failure in the placebo arm of a clinical trial with AECOPD patients [13]. In Norway, the antibiotic prescribing rate for lower respiratory tract infection is lower than in most European countries [30]. One explanation may be easy access to CRP testing, which has shown to influence the prescribing rate by reducing the unnecessary prescription of antibiotics in patients presenting with acute cough in primary care [31].

Systemic corticosteroids were more frequently prescribed than antibiotics. Although prescribing systemic corticosteroids in the management of exacerbations of COPD or asthma seems to be less controversial than the prescription of antibiotics [12,19], antibiotics have been shown to be the more frequently prescribed of these two medications in a study from Sweden [32]. A greater proportion of our patients had also been treated with antibiotics than with systemic corticosteroids the year prior to the baseline examination. The systematic information from pulse oximetry and CRP test might have contributed to a twist in the treatment in favor of systemic corticosteroids.

Treating asthma exacerbations with systemic corticosteroids is recommended in the current guidelines when short-acting beta 2-agonists do not give sufficient relief [18]. Among the patients only diagnosed with asthma by their GPs, prolonged expiration and diminished breath sounds were the strongest predictors, although not on the list of signs indicating severe asthma attacks in the guidelines from Global Initiative for Asthma (GINA) [18,19].

\section{Strengths and limitations}

As far as we know, this is the first observational study in primary care to investigate the predictors for treatment with antibiotics and systemic corticosteroids including patients with asthma, COPD or both in one patient sample. However, limitations in this study necessitate some caution when interpreting the results. The small number of patients included in the analysis made the results less reliable in particular after dividing the patients into asthma and COPD groups. CRP values $\geq 40 \mathrm{mg} / \mathrm{L}$ and 
$\mathrm{SpO} 2$ values $\leq 92$ were strongly associated with high prescribing rates of both antibiotics and systemic corticosteroids, and the predictive value of other findings may have been influenced by the co-presence of such findings. For instance, the finding of crackles was significantly associated with low oxygen saturation $(P=0.001)$, and this might have contributed to the high prescribing rate of systemic corticosteroids in the patients with crackles. However, crackles was still a significant predictor of systemic corticosteroid prescribing in the multivariable analysis.

This study does not show what is really going on in daily practice, but what may happen with decisions on prescribing when both CRP testing and pulse oximetry is carried out as a routine. Even when these tests are available they would not have been applied in the same way by the GPs in a real life situation. Pulse oximetry has so far not been frequently used in the assessment of exacerbations, although recommended in both the GOLD (Global Initiative for Chronic Obstructive Lung Disease) and GINA guidelines. In other settings, external factors such as short consultation times and the patient's social circumstances influence prescribing behavior [33].

The inclusion of both asthma and COPD patients may be regarded as a weakness of the study. On the other hand, this mix of patients reflects real life in primary care, where it is often difficult to decide which of the two diseases the patient suffers from. $\mathrm{FEV}_{1} / \mathrm{FVC} \geq 0.7$ had been found in some patients in the COPD group at baseline, and $\mathrm{FEV}_{1} / \mathrm{FVC}<0.7$ in some patients in asthma group. Some symptoms typical for COPD were registered with almost similar frequency in both groups, such as increased phlegm and purulence. This indicates that the classification of patients into COPD and non-COPD groups is not crystal clear and that some patients with $\mathrm{FEV}_{1} / \mathrm{FVC} \geq 0.7$ suffered from an early COPD. In the COPD group more than half of the patients had also been given an asthma diagnosis the previous 5 years. COPD was most frequently the last diagnosis of the two [3], and there had been a trend of change in diagnosis from asthma to COPD since 1995 [34]. Asthma can develop into COPD [35], and a tendency to choose an asthma diagnosis when COPD could be questioned was strengthened by the reimbursement regulations for respiratory medication introduced in Norway in 2006. When the study was carried out, costs of inhaled corticosteroids combined with long-acting $\beta_{2}$-agonists could be reimbursed, as a rule, only in patients with a diagnosis of asthma.

\section{Implications of the study}

The GPs relied on the findings by physical examination, $\mathrm{CRP}$ and pulse oximetry more than on the patient's respiratory symptoms when deciding type of treatment. While the usefulness of CRP is already strongly supported by recent evidence, the role of chest findings and oxygen saturation is not yet clear. Since GPs seems to heavily rely on chest findings in their treatment decisions, it will be interesting to evaluate their usefulness as clues for treatment for asthma and COPD in future studies. With more evidence available, it might be possible to decide whether or not the application of chest findings, CRP testing and pulse oximetry can lead to improved patient outcomes related to COPD and/ or asthma exacerbations.

\section{Conclusion}

In this study where CRP testing and pulse oximetry were carried out as routine, chest findings, together with the results of CRP and oxygen saturation were stronger predictors in choosing the type of treatment in patients suffering from exacerbation of asthma or COPD than were respiratory symptoms.

\section{Abbreviations}

COPD: Chronic obstructive pulmonary disease; AECOPD: Acute exacerbation of chronic obstructive pulmonary disease; GP: General practitioner; CRP: C-reactive protein; $\mathrm{FEV}_{1}$ : Forced expiratory volume in one second; FVC: Forces vital capacity; SpO2: Saturation of peripheral oxygen.

\section{Competing interests}

The authors declare that they have no competing interests.

\section{Authors' contributions}

The data collection was conducted by HM, who together with SA-A designed the study. These two authors had full access to all of the data and took responsibility for the integrity of the data and the accuracy of the data analysis. MS contributed to the study design, statistical analysis and the interpretation of the results and $J L$ took part in the interpretation and discussion of the results. All authors critically reviewed and approved the final manuscript.

\section{Acknowledgements}

This study received a grant from the Norwegian Research Council (202650/N50). The authors thank the participating patients and Nordbyen legesenter, Tromsø, Allmed legesenter, Hammerfest, Alta legesenter, Skedsmokorset legesenter, Lillestrøm legesenter, Langbølgen legesenter, Oslo and Gransdalen legesenter, Oslo for their participation in collecting data.

\section{Author details}

${ }^{1}$ General practice research unit, Department of Community Medicine, UIT Arctic University of Norway, Tromso, Norway. ${ }^{2}$ Department of Family Medicine, CAPHRI, Maastricht University, Maastricht, The Netherlands.

Received: 14 February 2015 Accepted: 10 March 2015

Published online: 24 March 2015

\section{References}

1. Rabe KF, Wedzicha JA. Controversies in treatment of chronic obstructive pulmonary disease. Lancet. 2011;378:1038-47.

2. Buist AS, McBurnie MA, Vollmer WM, Gillespie S, Burney P, Mannino DM, et al. International variation in the prevalence of COPD (the BOLD Study): a population-based prevalence study. Lancet. 2007;370:741-50.

3. Melbye H, Drivenes E, Dalbak LG, Leinan T, Hoegh-Henrichsen S, Ostrem A. Asthma, chronic obstructive pulmonary disease, or both? Diagnostic labeling and spirometry in primary care patients aged 40 years or more. Int J Chron Obstruct Pulmon Dis. 2011;6:597-603.

4. Reddel HK, Taylor DR, Bateman ED, Boulet LP, Boushey HA, Busse WW, et al. An official American Thoracic Society/European Respiratory Society statement: asthma control and exacerbations: standardizing endpoints for clinical asthma trials and clinical practice. Am J Respir Crit Care Med. 2009;180:59-99. 
5. The Norwegian Ministry of health. The Norwegian public health strategis for prevention and management of asthma and allergic diseases. Published May 2008. Publication code I-1134 B. 2014.

6. Miller MK, Lee JH, Miller DP, Wenzel SE. Recent asthma exacerbations: a key predictor of future exacerbations. Respir Med. 2007;101:481-9.

7. Al-ani S, Spigt M, Hofset P, Melbye H. Predictors of exacerbations of asthma and COPD during one year in primary care. Fam Pract. 2013;30:621-8.

8. Hurst JR, Vestbo J, Anzueto A, Locantore N, Mullerova H, Tal-Singer R, et al. Susceptibility to exacerbation in chronic obstructive pulmonary disease. N Engl J Med. 2010;363:1128-38.

9. Barnes PJ, Shapiro SD, Pauwels RA. Chronic obstructive pulmonary disease: molecular and cellular mechanisms. Eur Respir J. 2003;22:672-88.

10. Barnes PJ. Immunology of asthma and chronic obstructive pulmonary disease. Nat Rev Immunol. 2008;8:183-92.

11. Pearson M, Ayres JG, Sarno M, Massey D, Price D. Diagnosis of airway obstruction in primary care in the UK: the CADRE (COPD and Asthma Diagnostic/management REassessment) programme 1997-2001. Int J Chron Obstruct Pulmon Dis. 2006;1:435-43.

12. Global Initiative for Chronic Obstructive Pulmonary Disease (GOLD). Global strategy for the diagnosis, mamagement, and prevention of chronic obstructive pulmonary disease (revised 2011). 31-1-2012. [http://www.goldcopd.org/ guidlines-global-strategy-for-diagnosis-management.html]

13. Miravitlles M. [Treatment failure of acute exacerbations of chronic obstructive airways disease risk factors and clinical relevance]. Med Clin (Barc). 2002:119:304-14.

14. Anthonisen NR, Manfreda J, Warren CP, Hershfield ES, Harding GK, Nelson NA. Antibiotic therapy in exacerbations of chronic obstructive pulmonary disease. Ann Intern Med. 1987;106:196-204.

15. Blasi F, Ewig S, Torres A, Huchon G. A review of guidelines for antibacterial use in acute exacerbations of chronic bronchitis. Pulm Pharmacol Ther 2006;19:361-9.

16. Management of chronic obstructive pulmonary disease in adults in primary and secondary care. 2010. [http:,guidance.nice.org.uk/CG101]

17. Reddel H, Ware S, Marks G, Salome C, Jenkins C, Woolcock A. Differences between asthma exacerbations and poor asthma control. Lancet. 1999:353:364-9.

18. The global initiative for asthma. 2012. [http://www.ginasthma.org]

19. Pollart SM, Compton RM, Elward KS. Management of acute asthma exacerbations. Am Fam Physician. 2011;84:40-7.

20. Roede BM, Bindels PJE, Brouwer HJ, Bresser P, de Borgie CAJM, Prins JM Antibiotics and Steroids for Exacerbations of COPD in Primary Care: Compliance with Dutch Guidelines. Br J Gen Pract. 2006;56(530):662-5.

21. Llor C, Bjerrum L, Munck A, Hansen MP, Córdoba GC, Strandberg EL, et al. Predictors for antibiotic prescribing in patients with exacerbations of COPD in general practice. Ther Adv Respir Dis. 2013;7:131-7.

22. Goossens $H$, Ferech $M$, Vander SR, Elseviers M. Outpatient antibiotic use in Europe and association with resistance: a cross-national database study. Lancet. 2005;365:579-87.

23. Decramer M, Lacquet LM, Fagard R, Rogiers P. Corticosteroids contribute to muscle weakness in chronic airflow obstruction. Am J Respir Crit Care Med. 1994;150:11-6.

24. Similowski T, Suissa S. Systemic steroids in severe forms of COPD exacerbations: a question of balance? Eur Respir J. 2014;43:668-70.

25. Miller MR, Hankinson J, Brusasco V, Casaburi R, Coates A, Crapo R, et al. Standardisation of spirometry. Eur Respir J. 2005:26:319-38.

26. Macfarlane J, Lewis SA, Macfarlane R, Holmes W. Contemporary use of antibiotics in 1089 adults presenting with acute lower respiratory tract illness in general practice in the U.K.: implications for developing management duidelines. Respir Med. 1997;91(7):427-34.

27. Hopstaken RM, Butler CC, Muris JW, Knottnerus JA, Kester AD, Rinkens PE, et al. Do clinical findings in lower respiratory tract infection help general practitioners prescribe antibiotics appropriately? An observational cohort study in general practice. Fam Pract. 2006;23:180-7.

28. Jakobsen KA, Melbye H, Kelly MJ, Ceynowa C, Mölstad S, Hood K, et al. Influence of CRP testing and clinical findings on antibiotic prescribing in adults presenting with acute cough in primary care. Scand J Prim Health Care. 2010;28:229-36.

29. Coenen S, Van RP, Vermeire E, Hermann I, Denekens J. Antibiotics for coughing in general practice: a qualitative decision analysis. Fam Pract. 2000;17:380-5.
30. Butler CC, Rollnick S, Kinnersley P, Jones A, Stott N. Reducing antibiotics for respiratory tract symptoms in primary care: consolidating 'why' and considering 'how'. Br J Gen Pract. 1998;48:1865-70.

31. Cals JW, Butler CC, Hopstaken RM, Hood K, Dinant GJ. Effect of point of care testing for $C$ reactive protein and training in communication skills on antibiotic use in lower respiratory tract infections: cluster randomised trial. BMJ. 2009;338:b1374

32. Sundh J, Osterlund EE, Janson C, Montgomery S, Stallberg B, Lisspers K. Management of COPD exacerbations in primary care: a clinical cohort study. Prim Care Respir J. 2013;22:393-9.

33. Bradley CP. Factors which influence the decision whether or not to prescribe: the dilemma facing general practitioners. Br J Gen Pract. 1992:42:454-8

34. Haugen T, Bakken IJ, Storro O, Øien T, Langhammer A. Utilization of diagnostic tools and health care services for obstructive lung disease. Tidsskr Nor Laegeforen. 2008;128:2431-4.

35. Guerra S. Asthma and chronic obstructive pulmonary disease. Curr Opin Allergy Clin Immunol. 2009;9:4-9. 416.

\section{Submit your next manuscript to BioMed Central and take full advantage of:}

- Convenient online submission

- Thorough peer review

- No space constraints or color figure charges

- Immediate publication on acceptance

- Inclusion in PubMed, CAS, Scopus and Google Scholar

- Research which is freely available for redistribution 